\title{
Influence of Bay k 8644 on Aequorin-Loaded Human Platelets
}

\author{
Nobuyuki OGAWA and Hiroshi ONO* \\ Department of Pharmacology and Toxicology. Hatano Research Institute, Food and \\ Drug Safety Center, 729-5 Ochiai. Hadano. Kanagawa 257. Japan
}

Accepted July 14, 1989

\begin{abstract}
In aequorin-loaded human platelets, Bay $k 8644(1-100 \mu \mathrm{M})$ had no effect on the resting level of cytoplasmic $\mathrm{Ca}^{2+}$ and did not induce aggregation by itself. Though the rise of cytoplasmic $\mathrm{Ca}^{2+}$ and platelet aggregation induced by thrombin $(0.1 \mathrm{U} / \mathrm{ml})$ also was not inhibited by $1-10 \mu \mathrm{M}$ of Bay $\mathrm{k} 8644$, at concentration of 3-10 $\mu \mathrm{M}$, it dose-dependently reduced those induced by collagen $(5 \mu \mathrm{g} / \mathrm{ml})$. The present study shows that human platelets do not have dihydropyridine sensitive $\mathrm{Ca}$ channels.
\end{abstract}

It is well-known that $\mathrm{Ca}^{2+}$ plays an important role in platelet aggregation. Previous studies have shown that $\mathrm{Ca}$ antagonists such as verapamil, nifedipine and diltiazem inhibited platelet aggregation induced by several agonists $(1-3)$. However, high concentrations of $\mathrm{Ca}$ antagonists are required to inhibit platelet aggregation in comparison to the concentrations exhibiting effects on cardiac muscle and vascular smooth muscle. Fritschka et al. (4) recently reported that thrombin-induced ${ }^{45} \mathrm{Ca}$ influx into platelets was reduced by nitrendipine and considered that this effect of nitrendipine was due to the inhibition of voltage-dependent $\mathrm{Ca}^{2+}$ influx. However, there has been no identification of Ca channels on the plasma membrane of platelets by the radioligand binding technique (5). If the inhibitory effects of $\mathrm{Ca}$ antagonists on platelet aggregation are caused by their $\mathrm{Ca}$ channel blocking action, a $\mathrm{Ca}$ channel activator, such as Bay k 8644, may induce platelet aggregation. Therefore, we have examined whether Bay k 8644 induces platelet aggregation and increases cytoplasmic $\mathrm{Ca}^{2+}$ concentration by using aequorin-loaded human platelets and have studied the effects of Bay k 8644 on the rise of cytoplasmic $\mathrm{Ca}^{2+}$ and aggregation of human platelets caused by thrombin or collagen.

Blood was collected from healthy male

\footnotetext{
* To whom all correspondence should be addressed.
}

volunteers and anticoagulated with 1/9 volume of $3.8 \%$ sodium citrate. The blood was centrifuged at $200 \times \mathrm{g}$ for $10 \mathrm{~min}$ at room temperature to separate the plasma containing platelets. Platelets were prepared by centrifuging the plasma containing prostaglandin $\mathrm{E}_{1}(1 / 2 \mathrm{M})$ for $15 \mathrm{~min}$ at $800 \times \mathrm{g}$. Aequorin loading was performed according to Johnson et al. (6). After an initial wash with HepesTyrode's buffer containing $10 \mathrm{mM}$ EGTA and 1 $1 \mathrm{M}$ prostaglandin $\mathrm{E}_{1}$, platelets were incubated at $0^{\circ} \mathrm{C}$ in a loading solution containing 10 mM EGTA. 5 mM ATP. 1 $\mu$ M prostaglandin $E_{1}$ and aequorin for one hour. After loading. the platelets were recentrifuged and reincubated for one hour in recovery solution. containing $0.1 \mathrm{mM}$ EGTA, $10 \mathrm{mM} \mathrm{Mg}^{2+}$ and 1 «M prostaglandin $\mathrm{E}_{1}$. Platelets were centrifuged at $12000 \times \mathrm{g}$ for $12 \mathrm{sec}$ and resuspended in a Hepes-Tyrode's buffer containing $1 \mathrm{mM}$ $\mathrm{Ca}^{2+}$ and adjusted to $2 \times 10^{8}$ platelets $/ \mathrm{ml}$. The aequorin response and aggregation were simultaneously monitored by a Platelet lonized Calcium Aggregometer (ChronoLog).

Materials used in this study were obtained as follows: aequorin was purchased from Chrono-Log Co.; thrombin (human thrombin), from the Green Cross Co.; and collagen solution, from Hormon-Chemie München $\mathrm{GmbH}$.

Data are presented as mean \pm S.E. values. Differences of means were analyzed using the paired $t$-test and were considered significant 
when $P<0.05$.

Bay $k 8644$ had no effect on the resting level of cytoplasmic $\mathrm{Ca}^{2+}$ as monitored by the aequorin signal, nor did it induce aggregation by itself (Fig. 1). On the other hand, thrombin $(0.1 \mathrm{U} / \mathrm{ml})$ and collagen $(5 \mu \mathrm{g} / \mathrm{ml})$ obviously induced both responses (Fig. 1).

The effect of Bay k 8644 on cytoplasmic $\mathrm{Ca}^{2+}$ concentration and aggregation of platelets in response to thrombin and collagen is shown in Fig. 2. Preincubation with Bay $k$ 8644 for $3 \mathrm{~min}$ did not influence the rise of cytoplasmic $\mathrm{Ca}^{2+}$ concentration and aggregation of platelets induced by thrombin $(0.1 \mathrm{U} / \mathrm{ml})$. However, $3-10 \mu \mathrm{M}$ of Bay $\mathrm{k}$
8644 dose-dependently reduced the rise of cytoplasmic $\mathrm{Ca}^{2+}$ concentration and aggregation induced by collagen $(5 \mu \mathrm{g} / \mathrm{ml})$.

We observed that Bay k 8644 did not influence the resting level of cytoplasmic $\mathrm{Ca}^{2+}$ concentration and not induce aggregation in human platelets in vitro. Doyle and Ruegg (7) also reported that Bay k 8644 did not affect the resting level of cytoplasmic $\mathrm{Ca}^{2+}$ in human platelets using the fluorescent calcium indicator Quin 2. Therefore, it is suggested that the platelet plasma membrane does not possess dihydropyridine-sensitive $\mathrm{Ca}$ channels. It is also reported that $\mathrm{Ca}$ channels on the platelet plasma membrane were not
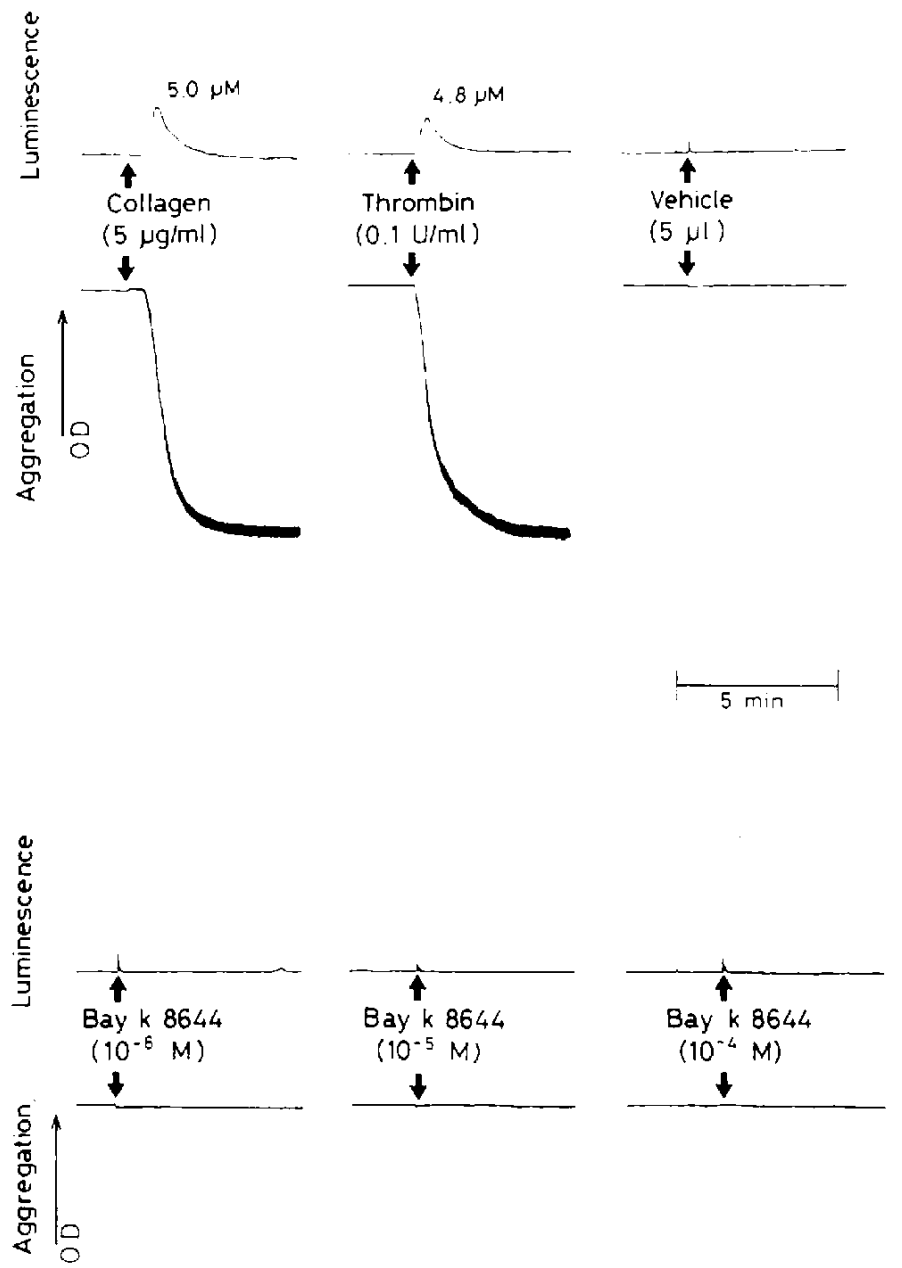

Fig. 1. Typical recordings of aequorin luminescence indicating intracellular $\mathrm{Ca}^{2+}$ concentration and optical density indicating aggregation level during stimulation with thrombin, collagen and Bay $k 8644$. 


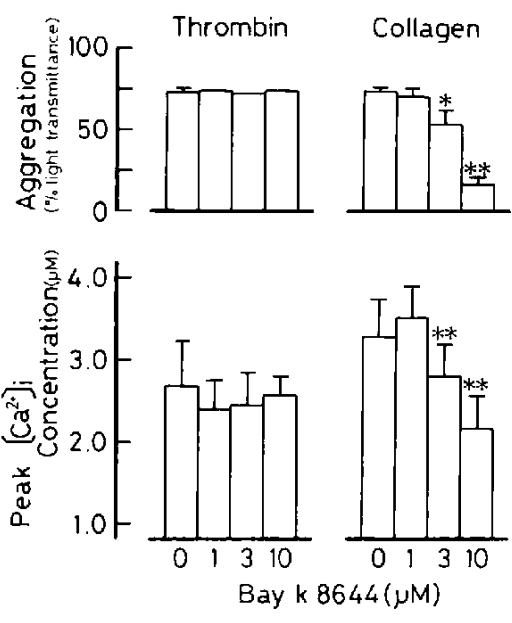

Fig. 2. Effect of Bay k 8644 on aggregation and the peak intracellular $\mathrm{Ca}^{21}$ concentration as indicated by aequorin in response to thrombin $(0.1 \mathrm{U} / \mathrm{ml}$, left side) and collagen $(5 \mathrm{rg} / \mathrm{ml}$, right side). Values reported are the mean $\pm S . E$, of four separate experiments. ${ }^{*} P<0.05,{ }^{* * P}<0.01$.

identified by the radioligand binding technique using dihydropyridines (5). However, thrombin is known to induce platelet aggregation following $\mathrm{Ca}^{2+}$ influx. Recently. Zschauer et al. (8) reported that the human platelet membrane possessed thrombin-activated $\mathrm{Ca}$ channels which were not inhibited by a 1.4-dihydropyridine Ca channel blocker. nisoldipine, but were inhibited by inorganic $\mathrm{Ca}$ channel blockers such as $\mathrm{Ni}^{2+}$, in an electrophysiological experiment.

Ware et al. (9) observed that aspirin treatment of human platelets reduced co!lageninduced aggregation but not the thrombininduced one. The present study also showed that Bay k 8644 inhibited collagen-induced aggregation but not the thrombin-induced one. Therefore. Bay $k 8644$ may influence the biosynthesis pathway of thromboxane $A_{2}$ induced by collagen. However, further studies are neccessary to elucidate the mechanism of action of Bay $k 8644$ in platelet aggregation. In conclusion, the present data support the result that the human platelet plasma membrane does not possess dihydropyridine- sensitive $\mathrm{Ca}$ channels.

Acknowledgment: This study was partly supported by Social Insurance Agency Contract Fund aided to Japan Health Sciences Foundation.

\section{References}

$1 \mathrm{Ono}, \mathrm{H}$. and Kimura, M.: Effect of $\mathrm{Ca}^{2+}-\mathrm{an}-$ tagonistic vasodilators, diltiazem, nifedipine. perhexiline and verapamil, on platelet aggregation in vitro. Arzneimittelforschung 31, 1131-1134 (1981)

2 Ware, J.A., Johnson, P.C., Smith, M. and Salzman, E.W.: Inhibition of human platelet aggregation and cytoplasmic calcium response by calcium antagonists: Studies with aequorin and Quin 2. Circ. Res. 59, 39-42 (1986)

3 Kiyomoto, A., Sasaki, Y., Odawara, A. and Morita, T.: Inhibition of platelet aggregation by diltiazem. Comparison with verapamil and nifedipine and inhibitory potencies of diltiazem metabolites. Circ. Res. 52 Supp. I, 115-119 (1983)

4 Fritschka, E., Kribben, A., Distler, A. and Philipp, $T$.: Inhibition of aggregation and calcium influx of human platelets by nitrendipine. J. Cardiovasc. Pharmacol. 9 Supp. 4, S85-S89 (1987)

5 Glossmann, H., Ferry, D.R., Lübbecke, F., Mewes, R. and Hofmann, F.: Calcium channels: Direct identification with radioligand binding studies. Trends Pharmacol. Sci. 3, 431-437 (1982)

6 Johnson, P.C., Ware, J.A., Cliveden, P.B., Smith, M., Dvorak, A.M. and Salzman, E.W.: Measurement of ionized calcium in blood platelets with the photoprotein aequorin: $\mathrm{Com}-$ parison with Quin 2. J. Biol. Chem. 260, 20692076 (1985)

7 Doyle, V.M. and Ruegg, U.T.: Lack of evidence for voltage dependent calcium channels on platelets. Biochem. Biophys. Res. Commun. 127, 161-167 (1985)

8 Zschauer, A., VanBreemen, C., Buhler, F.R. and Neison, M.T.: Calcium channels in thrombinactivated human platelet membrane. Nature 334, 703-705 (1988)

9 Ware, J.A., Johnson, P.C., Smith, M. and Salzmann, E.W.: Effect of common agonists on cytoplasmic ionized calcium concentration in platelets. Measurement with 2-methyl-6-methoxy-8-nitroquinoline (Quin 2) and aequorin. J. Clin. Invest. 77, 878-886 (1986) 